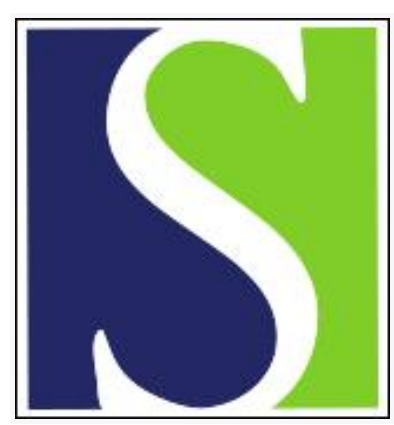

Scand J Work Environ Health 2005;31(3):227-232

https://doi.org/10.5271/sjweh.874

Issue date: Jun 2005

Primary prevention of cancer in relation to science, sociocultural trends and economic pressures

by Tomatis $\mathrm{L}$

Affiliation: Cave 25/r, I-34011 Aurisina (Trieste), Italy. Itomatis@hotmail.com

Key terms: cancer; discussion paper; economic pressure; economics; primary prevention; science; sociocultural trend

This article in PubMed: www.ncbi.nlm.nih.gov/pubmed/15999576

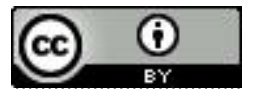




\title{
Primary prevention of cancer in relation to science, sociocultural trends and economic pressures ${ }^{1}$
}

\author{
by Lorenzo Tomatis ${ }^{2}$
}

Tomatis L. Primary prevention of cancer in relation to science, sociocultural trends and economic pressures. Scand J Work Environ Health 2005;31(3):227-232.

Our society has paid scant attention to the outcome of a recent meeting of a group of well-known scientists, economists, and artists for the centennial of the Nobel Prize (1). On that occasion 108 Nobel laureates signed a declaration stating that the most serious danger to world peace does not originate so much from irrational acts committed by single persons or single nations, but from a few large problems that cannot be solved by science and technology alone. These problems are the legitimate demands of the poor, the warming of the planet, and the dissemination of weapons. Poverty, environmental degradation, and the diffusion of weapons are forming a truly explosive mixture. Although poverty is widespread around the planet and there is a desperate need for funding food and public health programs, 2.3 billion US dollars a day, that is about 839 billion a year, were spent in 2001 for military purposes (2), about 2.4 billion US dollars a day in 2003, and most likely much more was spent in 2004.

It has been declared that globalization, economic growth, and the improvement in health are strictly correlated (3). A general consensus may exist that the spread of information and of education are fundamental to the improvement of living conditions and that globalization is, to a large extent, already a reality. It is not, however, clear that the massive, unopposed penetration and domination of powerful corporate interests throughout the entire planet will alleviate the economic and social unevenness between rich countries and those that are called developing countries. The distance that separates the richest countries from the poorest, and the rich from the poor within many industrialized countries, is increasing, and social and health inequalities are widening.
With this situation as background, primary prevention should be given high priority, as one of its main characteristics is its universality, since it protects the rich and the poor, the strong and the weak indiscriminately. By preventing the occurrence of disease it spares pain and sufferance. The primary prevention of infectious diseases has indeed progressed with the help of a general consensus and wide international collaboration as no one has ever contradicted the fact that bacteria, viruses, and parasites were equally pathogenic at all latitudes. If the primary prevention of infectious disease has not been applied with the same care and accuracy throughout the world, it is not because of doubts about the identified etiologic agents of the diseases, but rather as a consequence of a perverse combination of extreme poverty in certain countries, the irreducible selfishness of the rich countries, and the greed of multinational corporations.

The primary prevention of cancer, instead, has often stumbled on an obstacle course, primarily in the most industrialized countries. The identification of a chemical or physical agent as carcinogenic has been met with unjustified skepticism or open hostility from powerful groups that perceive such identification as jeopardizing certain, generally large, profits and financial interests. In contrast to what happened with the biological agents of disease, some chemical compounds have been recognized as carcinogenic in certain countries and not in others, and, even where they have been recognized as being carcinogenic, the permitted or accepted concentrations vary considerably, as if their carcinogenicity would disappear or change at certain borders.

The identification of an environmental agent as carcinogenic was, therefore, not necessarily followed by

1 This paper is based on a presentation given in honor of Professor Jorma Rantanen on 26 August 2004 at the Finnish Institute of Occupational Health in Helsinki, Finland.

2 International Society of Doctors for the Environment (ISDE), Arezzo, Italy.

Reprint requests to: Dr L Tomatis, Cave 25/r, I-34011 Aurisina (Trieste), Italy. [E-mail: ltomatis@ hotmail.com] 
the adoption of adequate preventive measures, and mostly not even by elementary prudence. In this context, the case of ionizing radiation is exemplary. Roentgen discovered X rays in 1895 (4), and 7 years later (an exceptionally short period between the introduction of a new agent into the environment and the demonstration of its noxiousness), the first two reports describing malignant tumors of the skin produced by ionizing radiation were published $(5,6)$. The observation of their carcinogenicity did not alert radiologists, health authorities, or the public as to the possible risks associated with their use and did not halt the rapid expansion of their use for diagnostic and therapeutic purposes. It was perhaps luckily so, given their immense usefulness, but, at the same time, we may also regret that this development happened in an almost total absence of caution. When I was a student, it was still rare to meet a radiologist who did not have serious lesions on his hands or some amputated fingers.

The case of ionizing radiation shows also the difficulties that are met when one tries to get the dangers of small doses accepted, in both the work and general environment. The carcinogenicity of natural radiation was in fact acknowledged only 40 years later, in 1942, when it was recognized as the cause of tumors in Schneeberg miners (7). It took several more decades before it was accepted that the general population was at risk from exposure to natural radiation at levels much lower than those found in the work environment (8).

Inconsistencies between the evidence of carcinogenicity and the adoption of preventive measures are also found for many other environmental carcinogens, to the point that it would actually be easier to prepare a list of missed chances than one of successes in primary prevention. To contrast the implementation of preventive measures that could involve modifications of certain industrial productions, part of the scientific establishment, either because of shortsighted stubbornness about achieving biological certainty or because of deliberate (but mostly surreptitious) alliances with corporate interests, did accept the contradiction of some of the strongest evidence in public health (ie, that efficient primary prevention against causative agents can be implemented before their mechanisms of action are fully understood). Supporting this stronghold of public health does not, in any way, belittle the value of basic research on mechanisms, but it could help to avoid the use of absolute mechanistic certainty as a pretext for an unlimited delay in the adoption of preventive measures.

Among the best-known unjustified delays in prevention is that of exposure to aromatic amines, for which it took a period of about 60 years before preventive measures were officially implemented. A similar case, although with a shorter delay, was that of bis-chloromethyl-ether (BCME) (9). The case of benzene is also a good example (10). In 1978 the concentration of benzene officially accepted was $10 \mathrm{ppm}$, sharply reduced from the $100 \mathrm{ppm}$ officially accepted in 1946, even though the knowledge about the carcinogenicity of benzene did not substantially differ between the two dates, nor was existing knowledge much more advanced in 1994, when a maximum acceptable concentration of 0.3 ppm was proposed. The hematotoxicity of exposure levels of $<1$ ppm was recently confirmed (11). The evolution of acceptable concentrations was, therefore, not driven by progress in the understanding of the mechanisms underlying the carcinogenicity of benzene, but was instead the result of a struggle for health by workers, unions, and concerned occupational health physicians against formidable economic interests.

A good example is also the case of diethylstilbestrol (DES), which was administered to pregnant women despite the warning from experimental evidence that DES was carcinogenic and that chemical carcinogens can cross the placenta and interact with fetal cells.

A common argument for ignoring the predictive value of evidence for carcinogenicity from long-term carcinogenicity tests was that the route of exposure was not the same and the type of tumors induced differed from those observed in humans. The experimental evidence of the multipotential carcinogenicity of benzene after its administration by the oral route demonstrated the fallacy of this argument (12). In other instances, the pretext was that the doses used experimentally were unrealistically high and administered for too long a time. Obviously the critics of long-term carcinogenicity tests were forgetting that most so-called occupational carcinogens had been identified in work conditions similar to experimental conditions, in other words, in relatively small groups exposed for a long time in confined spaces to high concentrations of a noxious compound.

To claim that the evidence of carcinogenicity obtained with the use of laboratory animals exposed to high doses for a long time was unfit to predict similar effects on humans at lower levels of exposure made it easier to ignore or deny the fact that the carcinogenic effect observed for workers exposed to high concentrations would predict an analogous effect on the general population, which is exposed to much lower levels.

In this way, two different yardsticks were emerging, a critical attitude toward experimental studies in which risks were maximized in order to observe a possible effect in a relatively limited number of exposed animals and a tacit, self-interested acceptance of high-risk situations in certain types of industrial production, an example of scientifically and ethically unacceptable incoherence.

For over a century, workers of many chemical and manufacturing industries have been involuntary guinea pigs for the general population, as they were the groups 
that allowed the identification of the carcinogenicity of chemicals that do not cease to be carcinogenic at lower concentrations in the general environment. Our society seems to have forgotten that, in the name of material progress and well being, from which we all profit, generations of workers have been sacrificed without recognition. Even the delayed pecuniary compensation for the health damages they suffered is encountering great difficulties. It is sufficient to compare the estimated number of cases of occupational cancer with the number of cases actually recognized as being entitled to compensation. In Italy, the data of the National Institute for Work Accidents (INAIL) for 1999 indicated that 390 cancer cases were officially recognized as occupational and entitled to compensation, while the total annual number of cases of occupational origin was estimated to be several thousands.

The case of asbestos dramatically illustrates both the discrepancy between scientific evidence of an adverse effect and its translation into adequate preventive measures and the irreducible determination of certain powerful economic interests to maintain, at all costs, the level of their profits $(13,14)$. How otherwise can one explain the fact that no international agreement yet exists that bans the production and use of asbestos or the fact that there is still an annual production of more than 2 million tons of asbestos? In addition some rich industrialized countries take advantage of the fact that occupational legislature in some poor countries is more permissive, or in some cases absent, and send their old ships, stuffed with asbestos, to these countries to be demolished (15).

Deafness toward the evidence of risk, which should have instead stimulated immediate action, is not limited to carcinogens, as has been shown by the case of thalidomide (16). Synthesized in 1953, its use spread swiftly in the following years until the early 1960s, when the evidence of its teratogenicity awoke the medical establishment, once more astonishingly inattentive. In retrospect, it was already known in 1954 that thalidomide caused peripheral neuritis and that, in parallel, there was evidence that exogenous agents like medical drugs, viral infections, and radiation could cause malformations during pregnancy. The first report of the teratogenic effect of thalidomide was submitted in June 1961 to The Lancet, which, at first, refused to publish it, as the journal had other priorities, but finally accepted it for publication 6 months later. As had happened for DES, warnings about the harmfulness of thalidomide were not seriously considered until the effects took on the dimension of a disaster.

In order to have a more comprehensive view of the contribution of primary prevention to the decrease in health risks, it would be important to know how many agents were actually prevented from entering the marketplace because of experimental evidence of carcinogenicity or mutagenicity. At the same time, it would also be useful to know how risk-benefit criteria are used by health authorities and regulatory agencies to allow the introduction of certain chemicals, in spite of evidence of their carcinogenicity or mutagenicity. Unfortunately this information, of which part is in private hands, remains undisclosed. At least one brilliant success of primary prevention can be pointed out, however. It is that regarding 4-aminodiphenyl, a success which also demonstrates the value of experimental animal data in predicting human risks. 4-Aminodiphenyl was produced and used in the United States starting in 1935. The United Kingdom was considering introducing its production in the early 1950s. In 1952 results of a longterm study on rats (17), confirmed 2 years later by a study on dogs (18), provided evidence for the carcinogenicity of 4-aminodiphenyl. In the United Kingdom the experimental evidence of carcinogenicity was considered sufficiently convincing to decide not to produce or use the compound. In the United States the first report of cases of urinary bladder cancer associated with occupational exposure to 4-aminodiphenyl was published in 1955 (19), and the production of the chemical was finally stopped.

The issue of the primary prevention of cancer is associated, to a considerable degree, to the attribution of risks. The attribution of risks can be made when information on several risk factors is available so that a distinction can be made between risks of different relevance and priorities before intervention can be proposed. The first time the difficult issue of attributable risks was approached in a comprehensive, although incomplete, way was in a publication by the World Health Organization (WHO) in 1964 (20), prepared by a group of experts chaired by Sir Richard Doll. Thereafter the best known and widely accepted assessment of attributable risks and of the preventable cancer cases was published by Doll \& Peto in 1981 (21). In that publication tobacco was considered responsible for $30 \%$ of cancer cases, diet for $35 \%$, with a range between $10 \%$ and $70 \%$, occupational risks for $1 \%$, and pollution for $2 \%$. It is of some interest that, in the 1964 WHO publication, air pollution was considered a relevant cause of lung tumors in humans, but its role appeared to be considerably dwarfed in 1981 .

At present, the best known and most credible list of human carcinogens is that based on the evaluations made by the International Agency for Research on Cancer (IARC) (22). Individual compounds or complex exposures are assigned to various groups according to the different levels of evidence of carcinogenicity available. Combining group 1 (human carcinogens) with 97 entries, group 2A (probable human carcinogens) with 65 entries, and group 2B (possible human carcinogens) 
with 241 entries gives a total of 403 environmental agents for which there is evidence of a causal association with cancer in humans of decreasing completeness from group 1 to group 2B.

It would be legitimate to ask whether the evidence of carcinogenicity for agents in group 2A, and even more in group $2 \mathrm{~B}$, is limited or inadequate with regard to the type of biological interaction of the chemical(s) or with regard to the extent and depth of the available data. The inclusion of an agent into one of the groups proposed by IARC has important consequences for the determination of attributable risks and translation into measures of primary prevention. In fact, mainly, if not exclusively, the risks associated with agents assigned to group 1 and 2A are considered attributable. The lack of certainty about the degree of evidence of carcinogenicity plays therefore against caution and against the efficacy of primary prevention.

IARC group $2 \mathrm{~B}$, which was originally conceived as a temporary grouping of agents for which further investigation was urgently needed, has now become a huge parking lot, with over 200 agents for which the available data are of variable quality and quantity. The chances that new data will become available on these agents in the near future appear remote (23). After the drastic reduction of independent laboratories interested in carrying out long-term carcinogenicity tests (the National Toxicology Program in the United States being a conspicuous exception), such tests are now mostly carried out by laboratories owned or financed by industry.

For many of these agents and mixtures, epidemiologic data are inadequate, but they cannot be considered equivalent to negative findings, nor can they be considered more relevant to public health than positive experimental findings (24). Given the difficulties of designing adequate studies, the general scarcity of funds and the perspective of obtaining results that are published only in journals with a low impact factor, agents of group $2 \mathrm{~B}$ have not raised the interest of epidemiologists, in spite of the fact that several of them may need indepth investigation without delay. Among these are acetaldehyde, acrilonitrile, chloroprene, carbon tetrachloride, 1,2-dichloroethane, hexachlorobenzene, lead, styrene, bitumen, and benzine. To this partial list, one can add a few compounds that have recently been downgraded from group 2B to group 3, namely, atrazine, phthalates, rock wool, and glass wool.

If the validity of the precautionary principle is not accepted, situations that can be defined for the group 2B type (ie, when experimental and epidemiologic data are relatively limited or do not reach the level of evidence that has been agreed upon as sufficient) create an impasse, the only outlet of which is the official perpetuation of risk conditions with possible ominous consequences for health. In practical terms, they are as difficult to deal with as the small doses of recognized human carcinogens. Admitting such difficulties, however, does not authorize a denial a priori of their possible etiologic role.

Among the incoherencies that characterize the current attitude of underestimating the importance of industrial chemicals and of interpreting their role in the origin of human cancers as only marginal, is a lack of attention to the fact that the universally recognized carcinogenic action of tobacco smoke is due to a considerable extent to the presence of small quantities of some of the chemicals identified as human carcinogens within the work environment and whose role is today underevaluated or denied. Eleven of the thirteen chemical human carcinogens (IARC group 1) found in tobacco smoke were originally identified in the work environment and labeled occupational carcinogens. The same holds true for most of the 30 chemicals pertaining to group $2 \mathrm{~A}$ and $2 \mathrm{~B}$ found in tobacco smoke.

An additional incoherence in the present attitude toward primary prevention concerns the way in which attributable risks are calculated as the method involves, in fact, taking very unequal evidence for various factors and treating it equally (25). While conclusive epidemiologic studies supporting a causal relationship between an agent and human cancers is considered a necessary requirement for declaring an agent carcinogenic to humans, tables of attributable risks are based on circumstantial or less than conclusive epidemiologic evidence of a causal relationship. If a causal association between an occupational or environmental exposure and human cancer is to be accepted, particularly robust evidence is required, whereas the evidence for the dietary contribution to cancer burden is mostly circumstantial and, in some instances, rather weak.

Against the background of a massive and ubiquitous advertisement promoted by the agrochemical and food industry proclaiming the preventive-protective virtues against cancer of certain dietary components, as if they were based on solid and incontrovertible evidence, there have been more cautious assessments, such as that by IARC in a monograph review of the role of fruits and vegetables (26). Furthermore, the attribution of most cancer cases to lifestyle, interpreted as being mainly related to personal choices, overemphasizes the individual's responsibility and draws attention away from the lack of commitment of health authorities and governments to public health and, at the same time, obscures the etiologic role of other risk factors (25). There is little doubt that it is justified and useful to promote a better social and sanitary education to make people more conscious and responsible in choosing their life habits. It is equally clear, however, that the emphasis given to lifestyle, to the detriment of information on the role of chemical pollutants, guarantees the undisturbed 
production of agents whose negative impact on health is kept secret or hidden or deliberately underestimated.

The effects of exposure to low or very low concentrations of environmental pollutants have begun only recently to be elucidated successfully. The best known are the actions of the so-called endocrine disruptors, but the case of cadmium is also particularly relevant. The carcinogenicity of cadmium in humans was revealed after relatively high occupational exposures. At much lower concentrations, however, such as those that may occur in the general environment, cadmium was shown to exert an inhibitory effect on postreplication mismatch DNA (deoxyribonucleic acid) repair (27). This effect may induce genomic instability that increases cellular susceptibility to the effects of other agents, thus contributing indirectly to an increase in the risk of cancer.

A different example of adverse effects caused by low doses is related to the possible prenatal origin of acute childhood leukemia. A retrospective analysis that took advantage of the availability of umbilical cord blood showed that certain translocations typical of myeloid leukemia were present already at birth in children who developed the disease up to 10 years later. The translocations, evidently persistent, are not sufficient per se to cause the disease, but, as does cadmium at very low concentrations, may greatly increase the risk of leukemia by inducing genomic instability $(28,29)$. Furthermore, both maternal exposure during pregnancy and paternal exposure to a series of chemicals before conception have been reported to be associated with ras proto-oncogene mutations in children who develop acute lymphatic leukemia (30).

The example of cadmium, while it shows the contribution that molecular studies can make to the identification and reconstruction of risk, points towards the role that exposure to low concentrations of noxious environmental agents can have in determining late pathological effects. The example of childhood leukemia reminds us that the carcinogenesis process may have its beginning far back in time, in the prenatal or even prezygotic period. These elements should be kept in mind if an attempt is made to draw up a credible table of attributable risks for use as orientation in primary prevention.

The systemic depreciation of the results of experimental carcinogenesis has coincided with an increase in human experimentation and the lack of constraint with which it is planned and implemented. Organized as if it would be the first stage of a controlled clinical trial, an experiment was carried out in which perchlorates were administered daily to volunteers, who received a compensation of USD 1000, to verify their potential toxicity in vivo. Similarly, hexavalent chromium has been given orally to volunteers to verify whether hexavalent chromium, a potent carcinogen if inhaled, maintains its toxicity also when given orally. Several studies on the possible short- and medium-term adverse effects of several pesticides and herbicides, including dichlorvos and a carbamate, aldicarb, have been carried out on human volunteers. Under pressure of environmental groups, the Environmental Protection Agency in the United States has recently asked the National Academy of Science whether it can accept and use results of research that involves the deliberate exposure of human subjects to potentially toxic substances (31). This rediscovery of elementary ethical principles provides a measure of how far we have gone from the spirit that we assume permeated the World Medical Association when it was drawing up the principles on which human experimentation should be regulated in Helsinki in 1964. These principles incorporated the so-called Nuremberg code, which, in turn, derived from the acts of the Nuremberg trial against Nazi doctors.

In spite of the great distance that separates present human experimentation from the extreme cruelty systematically employed in the German, but also the Japanese, prison camps, a not too thin thread connects what was judged and condemned in Nuremberg to what today is, or at least should be, regulated by ethics committees.

To have put informed consent as the first and most essential point among the 10 points of the Nuremberg code can be interpreted as recognition that the best and most valid defense that a person can have against imposed violence lays in his or her personal determination and capacity to resist, and, therefore, in his or her capacity and will to dissent. This interpretation brings with it an implicit mistrust of scientists, in the medical profession and in the basic structures of society. In fact, in spite of the fact that, in Germany and elsewhere, an effort was made to demonstrate that the horrors of the lagers, but also of the so-called eugenicists and of the elimination of the mentally feeble, was the action of a few deviants, it became impossible to deny that many people participated in these horrors, including numerous estimated members of the scientific and academic establishment (32).

If, for the protection of particularly defenseless and vulnerable people, we cannot trust those whose role is to protect health and to reduce human suffering, who can then be trusted? Can patients, defenseless and vulnerable, trust only themselves? In such a contest, the absolute priority given to the informed consent is also recognition of the fragility of our situation, poised between the so-called normality and the horror. It should be obvious that certain action should not be taken and that the priority given to the informed consent could be transformed in an ambiguous argument. Ambiguity appears to surround and then deeply penetrate scientific activity from various points. 
To the question "In order to carry out scientific research is it necessary to be motivated by something other than the passion for research?", one should perhaps answer that scientists should not only have a passion for research, but also a clear view of their obligations towards their fellow man and society.

\section{Acknowledgments}

I thank Elisabeth Heseltine for editing the manuscript.

\section{References}

1. Kondro W. Laurates plead for laws. Science 2002;294:2455.

2. The World Watch Institute. Vital signs 2003. New York (NY): WW Norton \& Co; 2003. p118.

3. Feachem RGA. Globalization is good for your health, mostly. BMJ 2001;323:504-6.

4. Roentgen WC. Ueber eiune neue Art von Strahlen [On a new type of radiation]. Sitzungsber Phys Med Gesellsch Wurtzb $1895 ; 132-41$.

5. Frieben A. Demonstration eines Cancroid der rechten Handruckens, das sich nach langdauernder Einwirkung von Roentgenstrahlen entwickelt hat [Demonstration of a cancroid of the right hand, which developed after a long lasting action of roentgen rays]. Fortschr Roentgenst 1902;6:106-11.

6. Sick H. Karzinom der Haut das auf dem Boden eines Roentgenulcus entstanden ist [Skin canrcinoma which developed over a roentgen ulcer]. Muench Med Wochenschr 1902;50:1445.

7. Scuttman W. Schneeberg lung disease and uranium mining in the Saxon Ore Mountain (Erzgebirge). Am J Ind Med 1993;23:355-68.

8. International Agency for Research on Cancer (IARC). Manmade mineral fibers and radon. Lyon: IARC; 1988. IARC Monographs on the evaluation of carcinogenic risks to humans, vol 43.

9. Tomatis L. The predictive value of rodent carcinogenicity tests in the evaluation of human risk. Ann Rev Pharmacol Toxicol 1979;19:511-30.

10. Imbriani M,Ghittori S, Pezzagno G, Capodaglio E, editors. Advances in occupational medicine and rehabilitation, volume 1. Pavia (Italy): Fondazione S Maugeri Edizioni; 1995.

11. Lan Q, Zhang L, Li G, Vermeulen R, Weinberg RS, Dosemeci $\mathrm{M}$, et al. Hematotoxicity in workers exposed to low levels of benzene. Science 2004;306:1774-6.

12. Maltoni C, Conti B, Scarnato C. Benzene: a multi-potential carcinogen - results of long-term bioassays performed at the Bologna Institute of Oncology. Am J Ind Med 1983;4:441-5.

13. Castleman B. Asbestos: medical and legal aspects. Clifton
(NJ): Law and Business Inc; 1983.

14. Ladou J. The asbestos cancer epidemics. Environ Health Perspect 2004;112:265-90.

15. Harris LV, Kahva IA. Asbestos: old foe in 21st century developing countries. Sci Total Environ 2003;307:1-9.

16. Dally A. Thalidomide; was the tragedy preventable? Lancet 1998;351:1197-9.

17. Walpole AL, Williams MHC, Roberts DC. The carcinogenic action of 4-aminodiphenyl and 3:2'-dimethyl-4-aminodiphenyl. Br J Ind Med 1952;9:255-63.

18 Walpole AL, Williams MHC Roberts DC. Tumours of the urinary bladder in dogs after ingestion of 4-amino-diphenyl. Br J Ind Med 1954;11:105-9.

19. Melick WJ, Escue HM, Narika JJ, Mezera RA, Wheeler EP. The first reported cases of human bladder tumours due to a new carcinogen—xenylamine. J Urol 1955;74:760-6.

20. World Health Organization (WHO). Prevention of cancer. Geneva: WHO; 1964. WHO Tech rep no 276.

21. Doll R, Peto R. The causes of cancer : quantitative estimates of avoidable risks of cancer in humans. J Natl Cancer Inst 1981;66:1191-308.

22. International Agency for Research on Cancer (IARC). Monographs on the evaluation of carcinogenic risks for humans, vol 1-85. Lyon: IARC; $1972-2004$

23. Karstadt M. Availability of epidemiologic data for chemicals known to cause cancer in animals: an update. Am J Ind Med 1998;34:519-25.

24. Tomatis L. Primary prevention protects public health. Ann N Y Acad Sci 2002;982:190-7.

25. Tomatis L, Huff J, Hertz-Picciotto I, Sandler DP, Bucher J, Boffetta P, et al. Avoided and avoidable risks of cancer. Carcinogenesis 1997;18:97-105.

26. International Agency for Research on Cancer (IARC). Fruit and vegetables. Lyon: IARC Press; 2003. IARC handbooks of cancer prevention, vol 8 .

27. Jin JH, Clark AB, Slebos RJ, Al-Refai H, Taylor JA, Kunkel TA, et al. Cadmium is a mutagen that acts by inhibiting mismatch repair. Nat Genet 2003;34:326-9.

28. Wiemels JL, Xiao Z, Buffler PA, Maia AT, Ma X, Dicks BM, et al. In utero origin of $\mathrm{t}(8 ; 21)$ AML1-ETO translocations in childhood acute myeloid leukemia. Blood 2002;99:3801-5.

29. McHale CM, Smith MT. Prenatal origin of chromosomal translocations in acute childhood leukaemias: implications and future directions. Am J Hematol 2004;75:254-7.

30. Shu XO, Perentesis JP, Wen W, Buckley JD, Boyle E, Ross JA, et al. Parental exposure to medications and hydrocarbons and ras mutations in children with acute lymphoblastic leukaemia: a report from the Children's Oncology Group. Cancer Epidemiol Biomarkers Prev 2004;13:1230-5.

31. Seelye KQ. EPA reconsiders human tests of pesticides. New York Times 2001;Dec:15.

32. Proctor RN. Nazi science and nazi medical ethics: some myths and misconceptions. Perspect Biol Med 2000;43:355-61. 